\title{
Representações sociais de mulheres idosas participantes de uma intervenção educacional em envelhecimento ativo
}

\author{
Social representations of elderly female participants in \\ an educational training program regarding active aging
}

Helio Marconi Gerth ${ }^{1}$, Paulo Renato Canineu ${ }^{1}$

\begin{abstract}
RESUMO
Introdução: Muitas estratégias têm sido usadas como forma de promover a saúde do idoso. Acredita-se que a informação é a principal ferramenta para conseguir tais objetivos. Dessa forma, utilizou-se como base a publicação "Envelhecimento ativo: uma política de saúde". Objetivo: Identificar as representações sociais de um grupo de mulheres idosas submetidas a uma intervenção educacional sobre envelhecimento ativo, verificando a reação dessas mulheres frente à metodologia aplicada. Métodos: A intervenção educacional foi realizada em seis encontros, realizados duas vezes por semana, com duração de uma hora cada e teve como teoria pedagógica a educação popular. $\mathrm{O}$ grupo estudado contou com a participação de 10 mulheres idosas, com idades entre 60 e 80 anos, frequentadoras de um programa de exercícios físicos oferecidos gratuitamente pela prefeitura de Sorocaba, São Paulo. Os dados foram coletados por meio de entrevista individual semiestruturada aplicada às participantes da pesquisa. Por se tratar de uma pesquisa transversal, exploratória e de perfil qualitativo, os dados foram organizados e analisados de acordo com o referencial teórico do discurso do sujeito coletivo, fundamentado na teoria das representações sociais e análise de conteúdo. Resultados: A metodologia utilizada foi muito bem aceita pelas participantes, que reagiram positivamente, acreditando que aprenderam coisas novas sobre os temas abordados. O conhecimento foi construído por meio de troca de ideias e experiências. O método favorece a união, fortalece as amizades, estimula a prática de exercícios físicos e a adoção de hábitos saudáveis. Conclusão: A metodologia mostrou-se adequada para o público estudado. As participantes gostaram muito e recomendam que outras pessoas também participem desse programa.
\end{abstract}

Palavras-chave: envelhecimento; saúde do idoso; educação em saúde; pesquisa qualitativa.

\begin{abstract}
Introduction: Numerous strategies have been employed as a means to promote health to the older population. It is believed that information is the primary tool in achieving this goal. Therefore, we used the text "Active aging: a policy framework" as a reference point. Objective: To identify the social representation of a group of elderly women who underwent educational training regarding active aging and to assess their response to this methodological approach, in order to develop an actual educational program for the elderly for future use. Method: This training was performed during six meetings, realized twice a week for one hour each day, which utilized the popular education as the pedagogic theory. The group assessed in this study was composed of 10 elderly women, between 60 and 80 years of age, who attended a community exercise program offered by the city of Sorocaba, São Paulo, Brazil. Data were obtained during individual semi-structured interviews. Since this trial consists of a transversal, exploratory, and qualitative study, data were organized and analyzed according to the theoretical reference discourse of collective subject, based on the theory of social representation and analysis of content. Results: The methodology was well accepted by the participants, who responded positively to the method and believed to have learned new information regarding the topics covered. New knowledge was constructed by exchanging ideas and experiences. The method favors networking, strengthens friendship bonds, stimulates physical activity, and promotes healthy habits. Conclusion: The methodology was appropriate for the population studied. Participants really enjoyed the program and recommend that other people attend it.

Keywords: ageing; elderly health; health education; qualitative research.
\end{abstract}

'Pontifícia Universidade Católica de São Paulo (PUC-SP), Faculdade de Ciências Médicas e da Saúde - Sorocaba (SP), Brasil. Contato: helio@hcsaude.com.br

Recebido em 23/09/2015. Aceito para publicação em 08/04/2016. 


\section{INTRODUÇÃO}

A população idosa vem crescendo a cada década. Estima-se que em 2030 o Brasil irá ter 32 milhões de idosos. ${ }^{1,2}$

$\mathrm{O}$ envelhecimento pode ser conceituado como um conjunto de modificações morfológicas, bioquímicas, fisiológicas e psicológicas que determinam a perda progressiva da capacidade de adaptação do indivíduo ao meio ambiente., ${ }^{2,3}$

Esses declínios físicos e fisiológicos somados à ausência de atitudes preventivas reduzem a qualidade de vida do idoso, geram perda progressiva da capacidade funcional e podem tornar o idoso dependente. Manter os idosos independentes é o primeiro passo para uma melhor qualidade de vida. ${ }^{3,4} \mathrm{O}$ envelhecimento bem-sucedido engloba três componentes principais: baixa probabilidade de doença e incapacidade, alta capacidade funcional física e cognitiva e engajamento ativo com a vida. ${ }^{5}$

Em 2002, a Organização Mundial da Saúde (OMS) conceituou o envelhecimento ativo, definindo-o como "o processo de otimização das oportunidades para a saúde, participação e segurança com o objetivo de melhorar a qualidade de vida à medida que se envelhece". ${ }^{4}$

A palavra "ativo" refere-se à participação contínua nas questões sociais, econômicas, culturais, espirituais e civis, e não somente à prática de exercícios físicos ou à capacidade de trabalho. ${ }^{4}$

Um dos mitos do envelhecimento é que muitos consideram ser tarde demais para se adotar um estilo de vida ativo nos últimos anos da vida. Pelo contrário, o envolvimento em atividades físicas adequadas, a alimentação saudável, a abstinência do fumo e do álcool e fazer uso de medicamentos sabiamente podem prevenir doenças e o declínio funcional e aumentar a longevidade e a qualidade de vida. ${ }^{4}$

Em 1986, a Carta de Ottawa traz para o âmbito da política a garantia da saúde, destacando a necessidade da participação comunitária como fundamental. Daí em diante governos têm estimulado ações educativas em saúde. ${ }^{6}$ Contudo, essas ações educativas devem possuir perspectiva dialógica, emancipadora, participativa, criativa e que contribua para a autonomia do usuário. ${ }^{7}$

Acredita-se que para adquirir uma mentalidade de prevenção de doenças e promover adequadamente a saúde do idoso, é fundamental a evolução e a disseminação do conhecimento sobre o envelhecimento. Há que se desenvolver ações que orientem os idosos e os indivíduos em processo de envelhecimento quanto à importância e à melhoria constante de suas habilidades funcionais, mediante a adoção precoce de hábitos saudáveis e a eliminação de comportamentos nocivos à saúde, assim como ao uso efetivo dos serviços de saúde e comunitários. Educar e capacitar idosos faz parte das propostas de ação do envelhecimento ativo., ${ }^{4,6}$

A educação popular busca trabalhar pedagogicamente formas coletivas de aprendizado e investigação, visando promover o crescimento da capacidade de análise crítica sobre a realidade e o aperfeiçoamento das estratégias de luta e enfrentamento. É uma estratégia de construção e participação popular no redirecionamento da vida social. Em vez de procurar difundir conceitos e comportamentos considerados corretos, ela procura problematizar, em uma discussão aberta, o que está incomodando e oprimindo, num processo contínuo de reflexão-ação-reflexão. ${ }^{7}$
Ações educativas em promoção da saúde com idosos devem ser realizadas por meio de encontros, espaços que vinculem afetivamente as pessoas e valorizem suas trajetórias de vida e seus saberes, garantindo o direito à informação e ao debate, favorecendo a reflexão sobre o envelhecimento em suas múltiplas faces e instigando atitudes participativas. ${ }^{6}$

Em 1961 surgiu na França a matriz da teoria das representações sociais (TRS), escrita pelo psicólogo social Serge Moscovici. Inicialmente a teoria não vingou, mas reapareceu com força nos anos $1980 .^{9-11}$

A pesquisa de Moscovici era voltada para fenômenos subjetivos, captados indiretamente, e dependia da interpretação do pesquisador, o que não era comum na psicologia daquela época. ${ }^{9}$

A TRS trabalha com o pensamento social em sua dinâmica e em sua diversidade. Constrói-se mais na esfera consensual, informal, onde qualquer pessoa pode falar de qualquer assunto. ${ }^{9,11}$

As representações sociais são definidas como sendo uma forma de conhecimento socialmente elaborado e compartilhado com um objetivo prático, equivalente aos mitos e às crenças da sociedade, ou seja, ao senso comum. ${ }^{10,12}$

O senso comum pode ser definido como um corpo de conhecimentos provenientes das experiências e das vivências que orientam o ser humano nas várias ações e situações de sua vida. Ele se constitui de opiniões, valores, crenças e modos de pensar, sentir, relacionar e agir. $\mathrm{O}$ senso comum se expressa na linguagem, nas atitudes e nas condutas e é a base do entendimento humano. ${ }^{13}$

Toda representação se origina de um sujeito (individual ou coletivo) e se refere a um objeto. A coleta de dados para esse tipo de enfoque geralmente é feita por meio de entrevistas, questionários, observações, pesquisas documentais e tratamentos de textos escritos ou imagéticos..$^{9,12}$

\section{OBJETIVOS}

Este trabalho pretendeu identificar as representações sociais de um grupo de mulheres idosas submetidas a uma intervenção educacional sobre envelhecimento ativo, verificando as reações dessas mulheres frente à metodologia aplicada para futuramente desenvolver um programa de educação em envelhecimento ativo voltado para idosos.

\section{MATERIAL E MÉTODOS}

A pesquisa foi aprovada pelo Comitê de Ética em Pesquisa com Seres Humanos da Faculdade de Ciências Médicas e da Saúde da Pontifícia Universidade Católica de São Paulo sob o parecer $n^{\circ} 866.720$ no dia 10 de novembro de 2014. Consiste em um estudo transversal, exploratório, de perfil qualitativo. ${ }^{13,14}$

Optou-se pela pesquisa qualitativa pelo fato da abordagem qualitativa entender que a realidade é subjetiva e múltipla, e que ela é construída de modo diferente para cada pessoa, trabalhando motivos, significados, aspirações, crenças, valores e atitudes. A investigação ocorre no ambiente natural e é preciso imergir na realidade empírica na busca de informações previstas ou não, onde os significados são mais importantes do que os resultados. ${ }^{13-15}$ 
A pesquisa foi realizada no Parque dos Espanhóis, em Sorocaba, São Paulo. Participaram da pesquisa 10 mulheres maiores de 60 anos, escolhidas aleatoriamente dentre as participantes de um programa de ginástica para terceira idade, oferecido gratuitamente pela prefeitura de Sorocaba.

Esse programa de ginástica existe há 23 anos, é exclusivamente feminino e atualmente conta com a participação de $60 \mathrm{mu}-$ lheres, sendo realizado 2 vezes por semana, das $7 \mathrm{~h} 15$ às $8 \mathrm{~h} 00$.

Além das aulas de ginástica localizada, também são organizadas atividades sociais como excursões e participação em bingos beneficentes, festas temáticas e bailes da terceira idade.

Optou-se por trabalhar com 10 indivíduos, baseado nas orientações do Caderno de Educação Popular e Saúde, ${ }^{7}$ que indica a formação de grupos com 8 a 12 participantes, e também na experiência de outros grupos que trabalham com metodologia similar, nos quais o grupo é disposto em círculo, há diálogo entre os participantes e valorização do conhecimento prévio, a exemplo do Grupo Encontros com a Saúde. ${ }^{16}$

Durante as intervenções, no quarto encontro, uma das colaboradoras precisou abandonar a pesquisa por problemas de saúde, permanecendo apenas nove colaboradoras até o final.

\section{A intervenção educacional}

A intervenção educacional proposta baseou-se nas recomendações da publicação "Envelhecimento ativo: uma política de saúde". ${ }^{4}$ Porém, por se tratar de uma publicação muito abrangente, este estudo limitou-se a abordar apenas os assuntos relacionados à prática de exercício físico e sua contribuição para o envelhecimento saudável e com qualidade de vida.

Utilizou-se como teoria pedagógica a educação popular, que valoriza o saber do educando e, através do diálogo e da reflexão, estimula a problematização. ${ }^{16,17}$

A intervenção foi realizada em seis encontros (aulas), com duração de uma hora, realizados duas vezes por semana, quartas e sextas, logo após a aula de ginástica, ou seja, das 8:00 às 9:00 h.

A coleta de dados foi realizada por meio de entrevista individual semiestruturada com as colaboradoras da pesquisa. ${ }^{18}$ As entrevistas foram gravadas (apenas áudio), transcritas e analisadas seguindo os critérios teóricos do discurso do sujeito coletivo de Lefèvre. ${ }^{10,19-21}$ Também foram usadas técnicas de análise de conteúdo. ${ }^{22,23}$

\section{Encontros educacionais}

Os encontros educacionais aconteceram nos meses de novembro e dezembro de 2014. No primeiro encontro o pesquisador explicou às colaboradoras sobre a metodologia proposta, os temas que seriam abordados e definiu o cronograma.

No segundo e no terceiro encontros abordou-se o tema: "exercício físico e envelhecimento". ${ }^{24}$ As cadeiras foram dispostas em forma de círculo, o pesquisador usou uma pergunta disparadora e iniciou-se um diálogo sobre o assunto em pauta. Todas as colaboradoras tiveram oportunidade de falar sobre suas experiências. Quando surgiam dúvidas o pesquisador perguntava para o grupo se alguém tinha a resposta e em seguida colaborava com orientações embasadas, esclarecen- do o assunto imediatamente. Para terminar, foi demonstrado para o grupo, em forma de diálogo, simples e resumido, as recomendações sobre exercício e envelhecimento publicadas pelo American College of Sports Medicine. ${ }^{24}$

No quarto e no quinto encontros foi abordado o tema "o papel do exercício físico como prevenção e tratamento da hipertensão e diabetes" ${ }^{24-27}$ Novamente dispostas em roda, o pesquisador fez uma pergunta disparadora e todas as participantes emitiram sua opinião. Nesse encontro a discussão foi bem ampla, pois surgiram dúvidas sobre alimentação, medicamentos e outras doenças associadas ao envelhecimento, mas o cronograma foi cumprido. Para terminar, foi demonstrado para o grupo, em forma de diálogo, simples e resumido, as recomendações sobre exercício e hipertensão e sobre exercício e diabetes tipo 2, publicadas pelo American College of Sports Medicine..$^{24-27}$

No sexto encontro foram realizadas as coletas de dados por meio de entrevistas individuais. ${ }^{18}$

\section{RESULTADOS E DISCUSSÃO}

Foram realizados seis encontros. Das 9 colaboradoras que participaram até o fim da pesquisa, 8 possuiam entre 70 e 75 anos, somente 2 concluiram o primeiro grau escolar e apenas 1 era solteira.

Durante os encontros, ao responder as perguntas disparadoras ou citar algum exemplo, os maridos eram sempre citados, pois não fazem exercício e não gostam de participar de eventos sociais.

Ribeiro $^{28}$ afirma que as mulheres realizam com mais frequência atividades ocupacionais e dedicam-se mais às atividades sociais, domésticas, aos trabalhos voluntários e de cuidados, porém, os homens praticam mais e com maior frequência atividade física.

No entanto, Silva ${ }^{29}$ e Araújo ${ }^{30}$ mostram em suas pesquisas um predomínio do público idoso feminino em atividades sociais, físicas, educacionais, etc. Isso se explica porque durante o envelhecimento ocorre um processo de feminização, ou seja, a expectativa de vida das mulheres é maior do que a dos homens. Esse é um fenômeno mundial.

A renda familiar predominante no grupo das colaboradoras é de um a três salários mínimos. Todas as colaboradoras moram próximo ao parque e vão a pé às aulas de ginástica.

Das participantes da pesquisa, a que está há menos tempo no grupo de ginástica, está há 6 anos e a mais antiga está desde a sua inauguração, há 23 anos. Todas relataram durante os encontros que as aulas são muito boas e que participar dessas aulas de ginástica faz bem para o corpo e para a mente, conforme pode-se observar nas falas: "Eu venho principalmente pela saúde, depois pela alegria e companheirismo da turma. É bom pra terceira idade"; "Os exercícios trazem muitos benefícios, muitos mesmo, faz bem pra saúde, faz bem pra cabeça, faz bem para o corpo, a gente volta pra casa muito animada pra pegar no serviço."

Nota-se que além de benefícios físicos, esse grupo de ginástica proporciona a suas participantes um espaço de convívio social muito interessante, e também muito importante para os idosos. 
A Tabela 1 demonstra a análise das ideias centrais expressas nos discursos referentes à pergunta "O que você achou do modelo educacional proposto? Aponte pontos positivos e negativos", que indicou três categorias temáticas: pontos positivos, pontos negativos e sugestões.

Discurso do Sujeito Coletivo 1 (DSC1): gostou do método, da aula em roda, da troca de experiências, da amizade - Colaboradora 1 (C1), Colaboradora 2 (C2), Colaboradora 3 (C3), Colaboradora 4 (C4), Colaboradora 5 (C5), Colaboradora 6 (C6), Colaboradora 7 (C7), Colaboradora 8 (C8), Colaboradora 9 (C9).

Achei ótimo. O que você fez aqui foi ótimo, sentamos em roda e cada uma expôs sua ideia, cada uma deu sua opinião. Dessa forma a gente fica mais à vontade, a gente conversa, parece que aproxima mais as pessoas, fica uma coisa mais unida. Diferente de uma palestra, que só o médico fala, aqui todas tiveram oportunidade de falar. Uma fala uma coisa, outra fala outra coisa e a gente vai captando, assim em grupo a gente sempre acha uma solução para os problemas. Foi legal de ver uma colega responder uma coisa e a gente responder diferente, porque cada uma tem ideia do que sente, do que é bom pra ela. Gostei e se tiver novamente pode me convidar que eu venho.

Discurso do Sujeito Coletivo 2 (DSC2): facilita o entendimento, esclarece dúvidas na hora, retém atenção, desenvolve e aprende (C1, C2, C3, C4, C5, C6, C7, C9).

Do jeito que você fez aqui, com poucas pessoas, é melhor porque quando você fala tá todo mundo ouvindo. Com muitas pessoas ninguém escuta ninguém. Numa palestra, você sabe, sempre tem uma do lado conversando, desvia a atenção, além disso, uma pergunta, outra pergunta, fica meio confuso, e às vezes você não consegue perguntar, o professor fala e a gente fica com dúvida. Assim com dez pessoas foi a melhor coisa que teve, você acertou bem nisso aí, pois você tem dúvida, fala e já esclarece na hora, isso facilita o entendimento da gente, aprende muito mais. Acho que foi legal também porque a coisa estava bem sintonizada, todas as conversas foram boas, as explicações foram boas, deu pra aprender muita coisa. Você explicou tudo o que uma pessoa de 60 anos precisa saber. Eu achei que com esse método eu me desenvolvi, pois eu tinha dificuldade pra falar e agora não tenho mais.

Discurso do Sujeito Coletivo 3 (DSC3): pontos negativos $(\mathrm{C} 1)$.

Teve gente que falou demais, mas acho que faz parte da idade, pois nessa idade as pessoas têm necessidade de falar mais. Acho que não teve ponto negativo a não ser isso de algumas pessoas falarem muito.

Discurso do Sujeito Coletivo 4 (DSC4): expansão do projeto (C4 e $\mathrm{C} 5)$.

Acho que você deve continuar fazendo esse programa, não deve parar, e ficaria melhor se a gente pudesse convidar uma amiga, e se todas as pessoas fizessem isso que a gente fez.

Observa-se que todas as colaboradoras relataram que gostaram muito do método, do formato em roda, das trocas de experiências e afirmaram que esse método aproxima as pessoas e estimula a amizade.

Outro fator positivo dessa metodologia é a busca conjunta por soluções, onde cada uma com sua experiência, e o professor com o conhecimento científico, contribuem com sugestões valiosas e realistas. A metodologia também facilita o entendimento dos assuntos abordados, pois são tratados dentro da realidade de cada um. As dúvidas são esclarecidas na hora, com a colaboração de todos.

O ponto negativo apontado por apenas uma das colaboradoras foi que algumas pessoas falam demais. Ao contrário disso, em outros trabalhos, o lado negativo ficou por conta dos professores que faltavam muito, dos alunos que abandonavam as aulas e não concluíam os trabalhos e dos assuntos abordados considerados menos interessantes. ${ }^{16}$

A análise das ideias centrais expressas nos discursos referentes à pergunta "Você recomendaria que seus amigos e familiares participassem desses encontros educacionais? Por que?" indicou apenas uma categoria temática: recomendação (Tabela 2).

Tabela 1. Distribuição das expressões chaves pelas categorias e subcategorias temáticas das opiniões sobre o modelo educacional proposto. Pontos positivos e negativos.

\begin{tabular}{lcc} 
Categoria temática & \multicolumn{1}{c}{ Subcategoria } & $\mathbf{N}^{\circ}$ de expressões chave \\
Pontos positivos & $\begin{array}{c}\text { Gostou do método, da aula em roda, da troca de } \\
\text { experiências, da amizade }\end{array}$ & 21 \\
& $\begin{array}{c}\text { Facilita o entendimento, esclarece dúvidas na hora, } \\
\text { retém atenção, desenvolve e aprende }\end{array}$ & 26 \\
Pontos negativos & Alguns falam demais & 3 \\
Sugestão & Expansão do projeto & 2 \\
Total & & 52
\end{tabular}


Tabela 2. Distribuição das expressões chaves pelas categorias e subcategorias temáticas sobre os motivos pelos quais os encontros educacionais são recomendados ou não.

$\begin{array}{lcc}\text { Categoria temática } & \text { Subcategoria } & \mathbf{N}^{\circ} \text { de expressões chave } \\ \text { Recomendação } & \begin{array}{c}\text { Recomendo, foi bom pra mim, } \\ \text { adquire conhecimento, incentiva prática de exercícios }\end{array} & 24 \\ \text { Total } & 24\end{array}$

Discurso do Sujeito Coletivo 1 (DSC1): recomendo, foi bom pra mim, adquire conhecimento e incentiva prática de exercício $(\mathrm{C} 1, \mathrm{C} 2, \mathrm{C} 3, \mathrm{C} 4, \mathrm{C} 5, \mathrm{C} 6, \mathrm{C} 7, \mathrm{C} 8, \mathrm{C} 9)$.

Recomendo e muito, pra todas as pessoas, pois foi muito bom pra mim, me fez muito bem, mas às vezes a pessoa não quer. Acho que é um conhecimento que todas as pessoas têm que ter o direito de ter. Porque vai esclarecer as pessoas que estão paradas e que não fazem nada para estar em atividade, e talvez a pessoa se anime a fazer ginástica. Esse programa é bom até pra cabeça da gente.

As colaboradoras recomendam os encontros educacionais, pois relatam que a experiência foi muito boa. Segundo elas, além de ser uma oportunidade de adquirir conhecimento, os encontros esclarecem as pessoas sobre assuntos relacionados à saúde e qualidade de vida, estimulando a prática de exercícios físicos e outros hábitos saudáveis.

Isso vem ao encontro da Política Nacional de Saúde do Idoso, que em sua diretriz "Promoção do Envelhecimento Saudável" recomenda que sejam desenvolvidas ações que orientem os idosos e os indivíduos em processo de envelhecimento quanto à importância da melhoria constante de suas habilidades funcionais, mediante a adoção precoce de hábitos saudáveis de vida e a eliminação de comportamentos nocivos à saúde (tabagismo, alcoolismo e automedicação). ${ }^{8}$

Segundo Assis, ${ }^{6}$ os hábitos saudáveis incluem alimentação balanceada, prática regular de exercícios físicos, convivência social, atividade ocupacional prazerosa e atividades que gerem controle do estresse.

\section{CONCLUSÕES}

As análises das representações sociais demonstraram que as colaboradoras obtiveram uma reação positiva frente ao modelo educacional proposto. A metodologia foi muito bem aceita, sentiram-se à vontade para expor suas opiniões e trocar experiências. Mesmo quando tiveram opiniões divergentes, o método participativo, com conhecimento compartilhado, facilitou o entendimento e a busca de soluções/respostas. As participantes sugerem a continuidade dos encontros educacionais e recomendam que outras pessoas participem, pois sentiram-se estimuladas a praticar exercícios físicos e adotar hábitos saudáveis.

$\mathrm{Na}$ minha visão de pesquisador, posso afirmar que a metodologia proposta se mostrou adequada para o trabalho educacional com idosos por causa da dinâmica atraente e envolvente do método. Sentadas em roda, todas as participantes se enxergavam. Ficaram um pouco tímidas no começo, mas depois foram se soltando. Após efetuar a pergunta disparadora, cada participante emitia sua opinião e contribuía com sua experiência. Abria-se então espaço para dúvidas e comentários complementares. Ao final dos comentários as dúvidas eram esclarecidas e encerrava-se o assunto com informações embasadas cientificamente. Em seguida iniciava-se novo assunto com outra pergunta disparadora.

Foram duas as dificuldades encontradas nesta pesquisa. A primeira delas diz respeito ao conteúdo abordado nos encontros. Tinha que ser um conteúdo interessante e significativo, numa abordagem adequada à faixa etária e ao grau de instrução das participantes. A outra dificuldade encontrada foi manter a discussão dentro do assunto em pauta. Algumas participantes contavam histórias e experiências muito demoradas, acabavam se perdendo e mudando de assunto. Isso prejudicava a atenção do grupo, exigindo intervenção do pesquisador.

Apesar das limitações, este estudo mostrou que desenvolver programas educacionais voltados aos idosos, com as características metodológicas aqui utilizadas, tem grandes chances de obtenção de sucesso. Outras pesquisas voltadas ao aprendizado e à retenção de conhecimento são recomendadas para dar mais subsídios a esses programas educacionais.

\section{REFERÊNCIAS}

1. Instituto Brasileiro de Geografia e Estatística (IBGE). Censo 2010 [Internet]. Rio de Janeiro: IBGE; 2011 [acesso em 13 out. 2014]. Disponível em: http://www.ibge.gov.br

2. Ferreira OGL, Maciel SC, Silva AO, Santos WS, Moreira MASP. O envelhecimento ativo sob o olhar de idosos funcionalmente independentes. Rev Esc Enferm USP. 2010;44(4):1065-9.

3. Ferreira OGL, Maciel SC, Costa SMG, Silva AO, Moreira MASP. Envelhecimento ativo e sua relação com a independência funcional. Texto Context Enferm. 2012;21(3):513-8.

4. World Health Organization (WHO). Envelhecimento ativo: uma política de saúde. Brasilia: -WHO; 2005.

5. Teixeira INDAO, Neri AL. Envelhecimento bem-sucedido: uma meta no curso da vida. Psicol USP. 1999;19(1):81-94.

6. Assis M. Envelhecimento ativo e promoção da saúde: reflexão para as ações educativas com idosos. Rev APS. 2005;8(1):15-24. 
7. Brasil. Ministério da Saúde. Secretaria de Gestão Estratégica e Participativa. Departamento de Apoio à Gestão Participativa. Caderno de educação popular em saúde. Brasília: Ministério da Saúde; 2007.

8. Gordilho A, Sérgio J, Silvestre J, Ramos LR, Freire MPA, Espindola N, et al. Desafios a serem enfrentados no terceiro milênio pelo setor saúde na atenção integral ao idoso. Rio de Janeiro: UnATI; 2000.

9. Arruda A. Teoria das representações sociais e teorias de gênero. Cad Pesqui. 2002;117:127-47.

10. Duarte SJH, Mamede MV, Andrade SMO. Opções teórico-metodológicas em pesquisas qualitativas: representações sociais e discurso do sujeito coletivo. Saúde Soc. 2009;18(4):620-6.

11. Moscovici S. Representações sociais: investigações em psicologia social. Petrópolis: Vozes; 2003.

12. Jodelet D. Representações sociais: um domínio em expansão. Rio de Janeiro: EDUERJ; 2002.

13. Minayo MCS. Análise qualitativa: teoria, passos e fidedignidade. Ciênc Saúde Coletiva. 2012;17(3):621-6.

14. Léo CCC, Gonçalves A. Modalidades metodológicas em pesquisa científica, a partir de recortes da experiência de saúde coletiva, epidemiologia e atividade física da UNICAMP. Rev Educ Fís UEM. 2010;21(3):411-41.

15. Turato ER. Métodos qualitativos e quantitativos na área da saude: definições, diferenças e seus objetos de pesquisa. Rev Saúde Pública. 2005;39(3):507-14.

16. Assis M. Promoção da saúde e envelhecimento: avaliação de uma experiência no ambulatório do Núcleo de Atenção ao Idoso da UnATI/UERJ. Tese (doutorado em Saúde Pública) - FIOCRUZ/Escola Nacional de Saúde Pública, Rio de Janeiro, 2004.

17. Chagas AM, Rocha AGV. A pedagogia de Paulo Freire e seus horizontes indicativos para uma dialogicidade igualitária e personalista. Griot Rev Filos. 2014;9(1):99-115.

18. Manzini E. Entrevista semi-estruturada: análise de objetivos e de roteiros. In: II Seminário Internacional sobre Pesquisa e Estudos Qualitativos SIPEQ. Bauru: USC; 2004. p. 10.

19. Lefevre F, Lefevre, AMC, Marques, MCC. Discurso do sujeito coletivo, complexidade e auto-organização. Ciênc Saúde Coletiva. 2009;14(4):1193-204.
20. Lefevre F, Lefevre AMC. O sujeito coletivo que fala. Interface Comun Saúde Educ. 2006;10(20):517-24.

21. Lefevre AMC, Crestana MF, Cornetta VK. A utilização da metododologia do discurso do sujeito coletivo na avaliação qualitativa dos cursos de especialização "Capacitação e Desenvolvimento de Recursos Humanos em Saúde-CADRHU”, São Paulo - 2002. Saúde Soc. 2003;12(2):68-75

22. Caregnato RCA, Mutti R. Pesquisa qualitativa: análise de discurso versus análise de conteúdo. Texto Context Enferm. 2006;15(4):679-84.

23. Campos CJG. Método de análise de conteúdo: ferramenta para a análise de dados qualitativos no campo da saúde. Rev Bras Enferm. 2004;57(5):611-4.

24. American College of Sports Medicine, Chodzko-Zajko WJ, Proctor DN, Fiatarone Singh MA, Minson CT, Nigg CR, et al. American College of Sports Medicine position stand. Exercise and physical activity for older adults. Med Sci Sport Exerc. 2009;41(7):1510-30.

25. Colberg SR, Albright AL, Blissmer BJ, Braun B, Chasan-Taber L, Fernhall B, et al. Exercise and type 2 diabetes: American College of Sports Medicine and the American Diabetes Association: joint position statement. Exercise and type 2 diabetes. Med Sci Sports Exerc. 2010;42(12):2282-303.

26. Pescatello LS, Franklin BA, Fagard R, Farquhar WB, Kelley GA, Ray CA. American College of Sports Medicine position stand. Exercise and hypertension. Med Sci Sport Exerc. 2004;36(3):533-53.

27. Tavares KO, Scalco JC, Vieira L, Silva JR, Bastos CCCB. Envelhecer, adoecer e tornar-se dependente: a visão do idoso. Rev Kairós Gerontol. 2012;15(2):105-18.

28. Ribeiro PCC, Neri AL, Cupertino APFB, Yassuda MS. Variabilidade no envelhecimento ativo segundo gênero, idade e saúde. Psicol Estud. 2009;14(3):501-9.

29. Silva CS, Silva AMF, Borges TM, Navarro F, Carneiro Júnior J. Efeitos da atividade física na capacidade psico-social e funcional do idoso. Rev Bras Prescr Fisiol Exerc. 2013;7(39):287-92.

30. Araújo LF, Coutinho MPL, Carvalho VAML. Representações sociais da velhice entre idosos que participam de grupos de convivência. Psicol Ciênc Prof. 2005;25(1):118-31. 